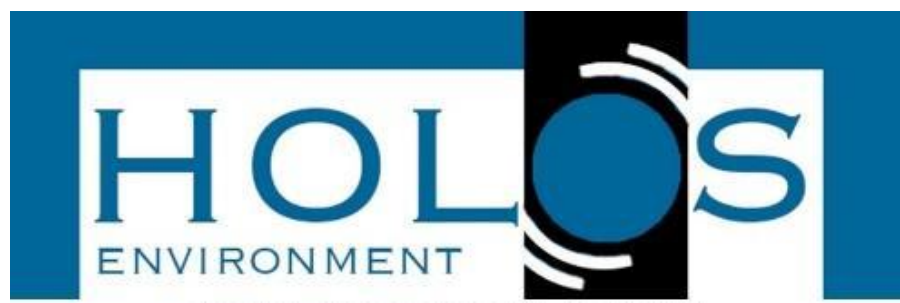

\title{
BANCO DE SEMENTES COM SERRAPILHEIRA COMO INDICADOR DE RESTAURAÇÃO FLORESTAL EM REGIÃO DE CERRADO NO MUNICÍPIO DE COXIM, MS
}

\section{SEED BANK WITH LITTER AS AN INDICATOR OF FOREST RESTORATION IN THE CERRADO REGION IN THE MUNICIPALITY OF COXIM MS}

\author{
Leonardo Neves de Freitas ${ }^{1}$; Poliana Ferreira da Costa ${ }^{1}$; Carla Messias Costa ${ }^{1}$; Bruna \\ Souza dos Santos ${ }^{2}$
}

Artigo recebido em: 27/10/2020 e aceito para publicação em: 02/02/2021. DOI: http://doi.org/10.14295/holos.v21i2.12432

\begin{abstract}
Resumo: O presente trabalho tem por objetivo avaliar o banco de sementes considerando a serrapilheira como indicador de restauração florestal da nascente do Córrego Criminoso, situada no município de Coxim, Mato Grosso do Sul - MS, Brasil. A área de estudo possui vegetação predominante de cerrado stricto senso. Para a obtenção dos dados realizou-se uma coleta de 40 amostras no entorno de duas das nascentes do Córrego Criminoso e foi realizado o acompanhamento da germinação, após 90 dias foi feito a identificação das espécies. Utilizou-se a ferramenta Qgis 2.18.21 para elaboração dos mapas, no sistema de projeção UTM Datum Sirgas 2000. Observou-se uma predominância de espécies herbáceas, sendo necessárias aplicações de técnicas de manejo para melhor eficiência da recuperação da área, e a partir dos mapas observa-se que a predominância de espécies herbáceas esta provavelmente relacionada a grandes áreas de pastagens presentes no entorno da nascente e reduzida presença de remanescentes florestais.
\end{abstract}

Palavras-chave: Germinação de sementes. Área degradada. Nascentes.

Abstract: The present work aims to evaluate the seed bank considering the litter as an indicator of forest restoration of the source of the Criminoso Stream, located in the municipality of Coxim, Mato Grosso do Sul MS, Brazil. The study area has predominant vegetation of cerrado stricto senso. In order to obtain the data, 40 samples were collected around two of the sources of the Criminoso Stream and the germination was monitored. After 90 days, the species were identified. In addition to using the tool Qgis 2.18.21 for elaboration of the maps, in the system of projection UTM Datum Sirgas 2000. Considering this, it was observed a predominance of herbaceous species, and it is necessary to apply of driving techniques to improve the efficiency of the area recovery, and from the maps it is observed that the predominance of herbaceous species is probably related to large grassland areas present in the spring and reduced presence of forest remnants.

Keywords: Seed germination. Degraded area. Springs.

\footnotetext{
'Universidade Estadual do Mato Grosso do Sul (UEMS), Dourados, MS, E-mails: (leonardo 209 freitas@hotmail.com, polianacostagestao@gmail.com, carlinhacostam@hotmail.com)

2 Universidade Estadual do Oeste do Paraná (UNIOESTE), Cascavel, PR; E-mails: (brusouzasantos@hotmail.com)
} 


\section{INTRODUÇÃO}

As atividades humanas em todos os seus aspectos ocasionam amplos impactos ambientais e a crescente extração dos recursos naturais é um dos grandes motivos para o atual cenário das áreas degradadas, pois o uso intensivo da natureza tem levado a ocorrência de extinção de várias espécies da flora e fauna, sendo espécies conhecidas ou ainda não identificadas. Geralmente em decorrências de corte, exploração madeireira, queima e expansão agropecuária (KOHLRAUSCH; JUNG, 2015).

Frente a crescente degradação surgiu á necessidade da criação de políticas e estratégias para recuperação ou restauração das áreas degradadas. "O Art $\cong 2$ que institui o sistema Nacional de unidades de Conservação define restauração como: Restituição de um ecossistema ou de uma população silvestre degradada o mais próximo possível da sua condição original" (BRASIL, 2000, Art $2^{\circ}$ XIV).

Contudo a conservação da mata ciliar próxima as nascentes, se mostra fundamental no papel de sua função ambiental, como na qualidade da água, estabilização do solo, regularização do regime hídrico, além de servir de corredores para o movimento da fauna, como também para a dispersão vegetal (ALVARENGA et al., 2006).

Para atingir o objetivo da restauração são utilizadas técnicas como plantio em núcleos, que segundo Minella e Bundchen (2015), possibilitam o aumento da biodiversidade local, obedecendo aos estágios naturais da sucessão ecológica de uma floresta nativa, onde os núcleos criados atrairão biodiversidade das áreas circundantes. Uma segunda técnica utilizada é a semeadura direta que se baseia na implantação de espécies sem o prévio revolvimento do solo com arados e grades. Além da regeneração natural que é fundamental, pois proporciona interação de processos naturais, e restabelece o ecossistema natural (FERREIRA et al., 2010).

Todavia, para se obter informações sobre o processo de restauração de uma área degradada e a sua capacidade de resiliência, utiliza-se como indicador a avaliação do banco de sementes, que pode inferir sobre o potencial de regeneração da área degradada e a sua futura comunidade de plântulas. A avaliação do banco de sementes é essencial, pois a mesma expressa o desempenho natural da vegetação e indica o potencial de reação face às adversidades de uma comunidade e de seus indivíduos (COSTA, 2017).

Neste sentido, buscou-se avaliar o banco de sementes considerando a serrapilheira em área de restauração florestal, no entorno de duas nascentes da microbacia do córrego 
Criminoso, no município de Coxim, no estado do Mato Grosso do Sul e realizar a quantificação e identificação das espécies germinadas e classificação quanto à origem, síndrome de dispersão e forma de vida. Além de averiguar a condição de conservação do banco de sementes.

\section{MATERIAL E MÉTODOS}

\section{1 Área de estudo}

O trabalho foi realizado no município de Coxim região norte do estado de Mato Grosso do Sul, que detém uma extensão territorial de $6.409,224$ km², com uma população estimada de 33.516 habitantes para o ano de 2018, e com densidade demográfica de $5,02 \mathrm{hab} / \mathrm{km}^{2}$ (IBGE, 2010).

A área de estudo comporta a microbacia do Córrego Criminoso conforme mostra a (Figura 1) fazendo parte da Bacia Hidrográfica do Paraguai, sub-bacia do Rio Taquari entre os paralelos $18^{\circ} 27^{\prime} 49^{\prime \prime}$ e $18^{\circ} 29^{\prime} 21^{\prime \prime}$ latitude sul e os meridianos $54^{\circ} 43^{\prime} 56,7^{\prime \prime}$ e $54^{\circ} 45^{\prime} 13,9$ de longitude oeste que dispõe de uma área de 28 ha e 5,5 de extensão (BRASIL, 1990).

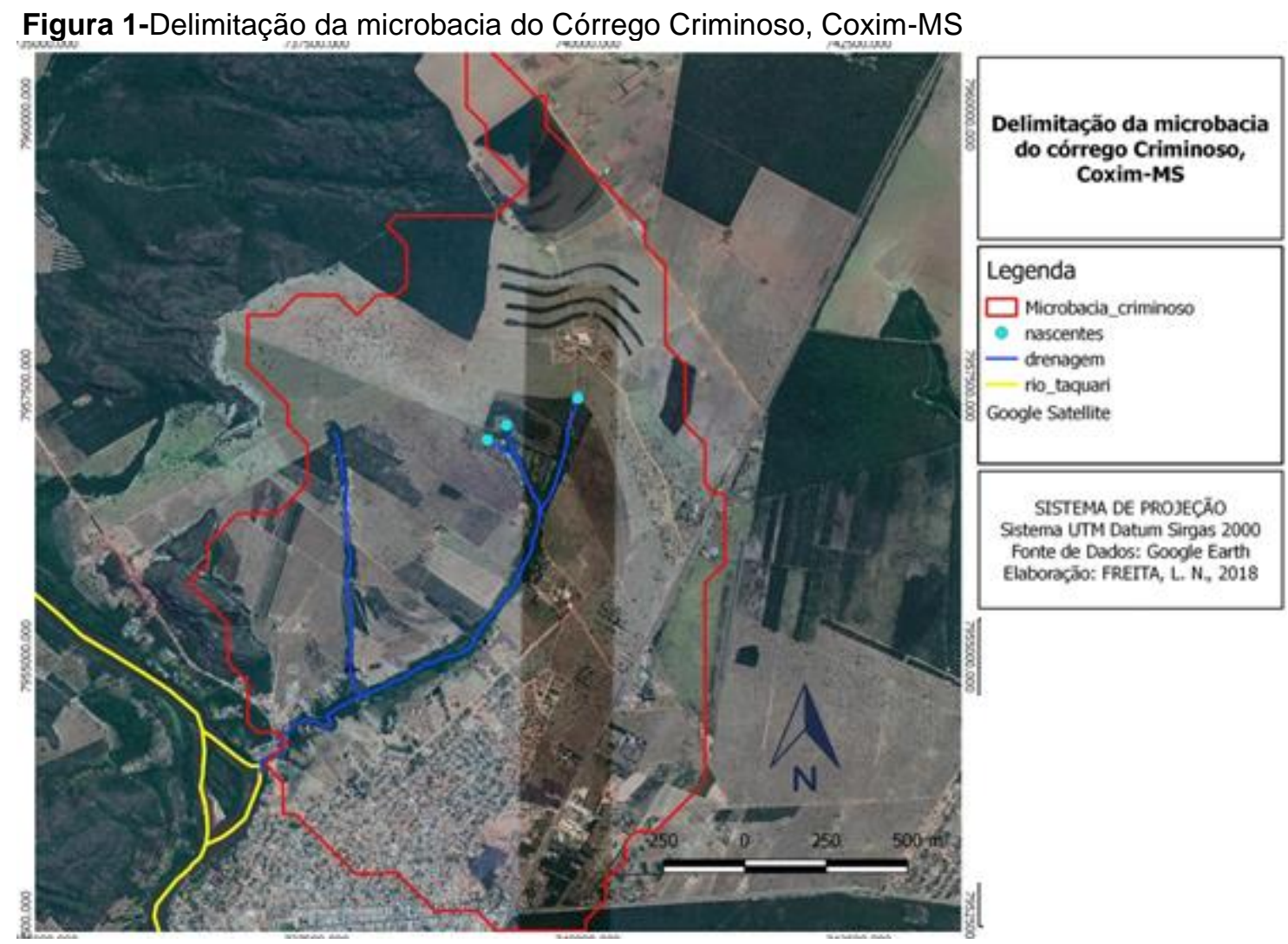

Fonte: Elaborado pelos autores. 
A vegetação predominante na área é o cerrado stricto sensu, com o predomínio de pecuária, lavoura, urbanização e alguns remanescentes florestais tendo como tipo de solo o arenoso (GUNTZEL et al., 2011).

O clima da região segundo a classificação de Koppen é de categoria AW, marcado por estação pluviosa no verão, entre os meses de novembro a abril e seca no inverno no período de maio a outubro (ZAVATTINI, 2009).

\subsection{Mapeamento da área de estudo}

Para a construção dos mapas, foram utilizadas imagens do Google Earth e o processamento das imagens foi realizado com o auxílio do software Qgis 2.18.21 e o sistema de projeção UTM Datum Sirgas 2000.

\subsection{Coleta do banco de sementes}

As coletas para avaliação dos bancos de sementes foram realizadas em setembro de 2017, foram coletadas 40 amostras no entorno de duas das nascentes do córrego Criminoso, em pontos escolhidos de forma aleatória. Em cada ponto foram abertas trincheiras verticais, onde foi coletado o solo em uma área superficial de $30 \times 30 \mathrm{~cm}$, a uma profundidade, de 0 a $5 \mathrm{~cm}$, considerando-se a serrapilheira. $O$ material coletado foi acondicionado em sacos plásticos e levado para o viveiro com sombrite a $50 \%$ da Universidade Estadual do Mato Grosso do Sul-UEMS, sendo dispostos em bandejas de plásticos $(30 \times 22 \times 7 \mathrm{~cm})$ devidamente perfuradas. As amostras foram irrigadas e monitoradas diariamente por um período de aproximadamente três meses (90 dias). método utilizado para identificação após a emergência de plântulas ou germinação foi o sugerido por Gross (1990) e Brown (1992). Após três meses foi realizada a identificação e quantificação das plântulas emergentes.

\subsection{Forma de identificação do banco de sementes}

A identificação das espécies foi efetuada por meio de especialistas e algumas espécies em comparação com o acervo do herbário da Universidade Federal da Grande Dourados, Dourados-MS. A classificação das famílias das plântulas emergentes ocorreu 
conforme Angiosperm Phylogeny Group IV (APG IV, 2016). Os nomes das espécies foram confirmados e/ou atualizados em consulta ao banco de dados da Lista de Espécies da Flora do Brasil 2020 (LEFB, 2018). As espécies também foram avaliadas conforme a sua síndrome de dispersão, adotando os critérios morfológicos dos frutos, definidos por Van Der Pijl (1982), como anemocóricas, zoocóricas, e autocóricas, além de serem classificadas quanto à forma de vida e a origem. Para isso, utilizou-se como referência os trabalhos de Oliveira e Paula (2001), Stefanello et al. (2010), bem como o Anexo da Resolução SMA 08, de 31/01/2008 (BRASIL, 2012).

\subsection{Aplicação do Índice de Shanoon}

Para análise da diversidade florística do banco de sementes aplicou-se o índice diversidade de Shannon, citado por Magurran (1988), onde se utilizou o software Microsoft Excel para aplicação da seguinte fórmula.

$H=-\sum_{i=1}^{S} p_{i} \operatorname{Ln} p_{i}$

Onde: $\mathrm{H}$ é índice de diversidade de shannon; S: É o número de espécies; In é o logaritmo neperiano; $\mathrm{pi}$ = ni/N; ni é o número de indivíduos amostrados da espécie i; e $\mathrm{N}$ é o número total de indivíduos amostrados.

Visto que quanto maior o valor de $\mathrm{H}^{\prime}$, maior a diversidade florística e mais equilibrada a distribuição das abundâncias entre as espécies (OLIVEIRA e ROTTA, 1982).

\section{RESULTADOS E DISCUSSÃO}

\subsection{Classificação das espécies}

O banco de sementes resultou na germinação de um total de 551 plântulas num total de 3,6 $\mathrm{m}^{2}$, o equivalente a 153 ind./m² semelhante ao encontrado por Braga et al. (2008), que na avaliação da composição do banco de sementes de uma Floresta Semidecidual Secundária quantificou 20 espécies, 17 gêneros e 13 famílias em 101,6 ind/m².

$\mathrm{Na}$ composição florística do banco de sementes da área em regeneração na nascente do Córrego Criminoso foram encontradas 9 famílias distribuídas em 28 espécies e 5 gêneros. As plântulas germinadas no banco de sementes do Córrego Criminoso foram 
identificadas em nível de família, gênero e espécie juntamente com especificações no que diz respeito a sua origem, forma de vida e síndrome de dispersão, e duas das espécies só foi possível a identificação a nível de família e outras cinco a nível de gênero. As espécies encontradas foram classificadas conforme está apresentado na (Tabela 1).

Tabela 1- Relação e classificação das espécies encontradas no banco de sementes da área de restauração da nascente do córrego Criminoso, no município de Coxim, Mato Grosso do Sul, Brasil

\begin{tabular}{|c|c|c|c|c|c|}
\hline Famílias & Taxa & FV & $\mathbf{O}$ & SD & $\mathbf{N I}$ \\
\hline Asteraceae & Bidens pilosa L. & Heb & Nat & An & 50 \\
\hline Asteraceae & Conyza bonariensis (L.) Cronquist & Heb & Ntv & An & 21 \\
\hline Asteraceae & Chromolaena odorata (L.) R.M.King \& H.Rob & Arb & Ntv & An & 2 \\
\hline Asteraceae & Gamochaeta pensylvanica (Willd.) & Heb & Ntv & An & 1 \\
\hline Asteraceae & Emilia fosbergii Nicolson & $\mathrm{Heb}$ & Ntv & An & 1 \\
\hline Asteraceae & Galinsoga parviflora Cav. & Heb & Nat & An & 1 \\
\hline Cyperaceae & Cyperus brevifolius (Rottb.) Endl. ex Hassk.. & Heb & Ntv & An & 89 \\
\hline $\begin{array}{l}\text { Cyperaceae } \\
\text { Cyperaceae }\end{array}$ & $\begin{array}{l}\text { Fimbristylis miliacea (L.) Vahl } \\
\text { Cyperaceae sp. }\end{array}$ & $\underset{*}{\mathrm{Heb}}$ & $\underset{*}{\mathrm{Ntv}}$ & $\underset{*}{\operatorname{An}}$ & $\begin{array}{l}75 \\
12\end{array}$ \\
\hline Cyperaceae & Cyperus aggregatus (Willd.) Endl. & Heb & $\mathrm{Ntv}$ & An & 8 \\
\hline $\begin{array}{l}\text { Cyperaceae } \\
\text { Fabaceae }\end{array}$ & $\begin{array}{l}\text { Cyperus Luzulae (L.) Retz. } \\
\text { Fabaceae sp. }\end{array}$ & $\underset{*}{\mathrm{Heb}}$ & $\underset{*}{N t v}$ & $\underset{*}{\text { Aut }}$ & $\begin{array}{l}7 \\
2\end{array}$ \\
\hline Fabaceae & Mimosa pudica L. & Heb & Ntv & Aut & 2 \\
\hline Fabaceae & Bauhinia variegata $\mathrm{L}$. & Arv & Ntv & Aut & 1 \\
\hline Fabaceae & $\begin{array}{c}\text { Chamaecrista fagonioides (Vogel) H.S.Irwin \& } \\
\text { Barneby }\end{array}$ & $\mathrm{Heb}$ & Ntv & Aut & 1 \\
\hline Fabaceae & Desmodium barbatum (L.) Benth. & Heb & $\mathrm{Ntv}$ & Zoo & 1 \\
\hline Melastomataceae & Tibouchina sp. & * & * & * & 2 \\
\hline Poaceae & Paspalum sp. & * & * & * & 216 \\
\hline Poaceae & Digitaria horizontalisWilld. & $\mathrm{Heb}$ & Ntv & Aut & 15 \\
\hline Poaceae & Urochloa decumbens Marrone \& Zuloaga & Heb & Exo & $\mathrm{n}$ & 12 \\
\hline Poaceae & Digitaria ciliaris (Retz.) Koeler & Heb & Ntv & An & 2 \\
\hline Poaceae & Saccharum Villosum Steud. & Heb & Ntv & An & 2 \\
\hline Portulacaceae & Portulaca oleracea L. & $\mathrm{Heb}$ & Ntv & Aut & 4 \\
\hline Portulacaceae & Portulaca sp. & * & * & * & 1 \\
\hline Rubiaceae & Borreria latifolia (Aubl.) K.Schum. & Heb & Ntv & An & 15 \\
\hline Rubiaceae & Richardia brasiliensis Gomes & Heb & Ntv & An & 2 \\
\hline Solanaceae & Solanum americanum Mill. & $\mathrm{Heb}$ & Ntv & Zoo & 2 \\
\hline Urticaceae & Cecropia pachystachya Trécul & Arv & Ntv & Zoo & 4 \\
\hline
\end{tabular}

Número de Indivíduos (NI); Forma de Vida (FV); Arbóreo (Arv); Arbustivo (Arb); Herbáceo (Heb); Síndrome de dispersão (SD); Anemocórica (An); Zoocórica (Zoo); Autocórica (Au); Origem (Or); Nativa (Ntv); Naturalizada (Nat) e Exótica (Exo).

\subsection{Análise da diversidade de famílias encontradas no banco de sementes}

Considerando as nove famílias amostradas, as que obtiveram maiores ocorrências de germinação foram Poaceae com 247 indivíduos, Cyperaceae 191 e Asteraceae 76. Outra família que apresentou uma quantidade de indivíduos relevante foi Rubiaceae 17, 
como também houve famílias que obtiveram menores incidências de germinação, como é o caso das famílias Fabaceae, Portulacaceae Urticaceae, respectivamente 7, 5 e 4 indivíduos e Melastomataceae e Solanaceae com apenas 2 indivíduos. Como demonstra a (Figura 2).

Figura 2- Quantidade de indivíduos por família encontrados no banco de sementes amostrado na nascente do Córrego Criminoso

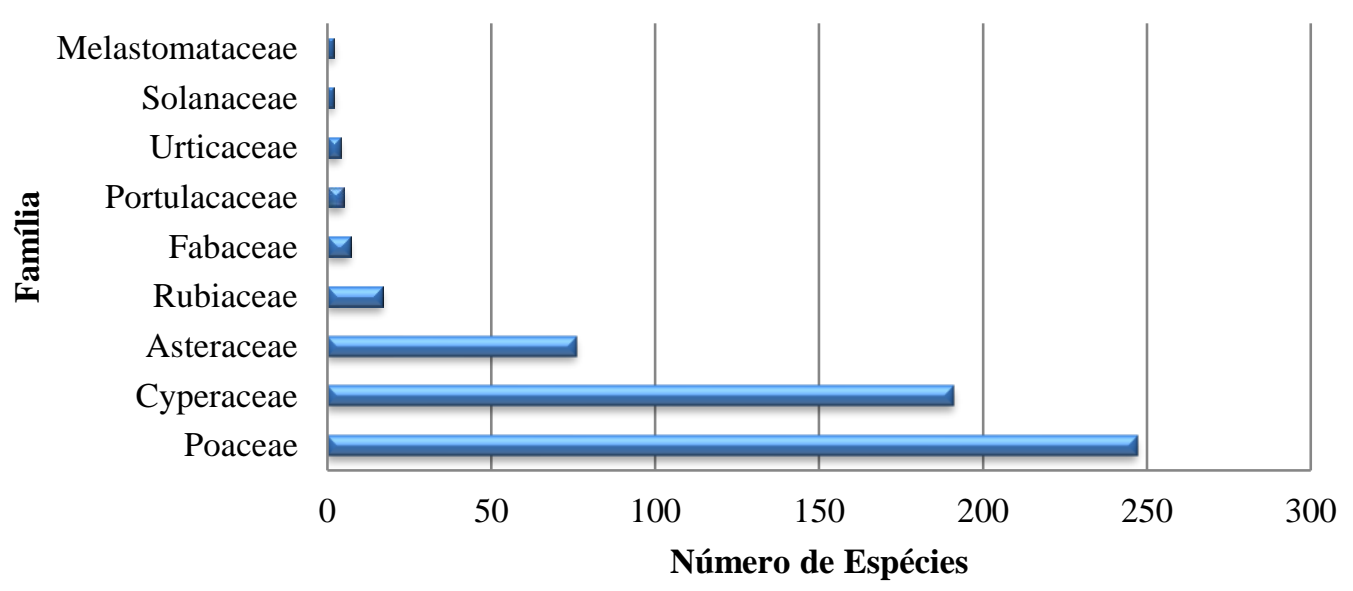

Fonte: Elaborado pelos autores.

A riqueza florística encontrada no banco de sementes apontou semelhança aos estudos realizados por Souza (1996) e Chami (2008), sendo as famílias mais abundantes Poaceae, Cyperaceae e Asteraceae.

Segundo Andrade (2015) um dos fatores que podem ter sido determinantes para a abundância das famílias Asteraceae e Poaceae, pode estar associado a suas características, como a dispersão das sementes pelo vento.

De acordo com Neto et al. (2010), as famílias Asteraceae, Fabaceae e Solanaceae são comumente encontradas em pastagens degradadas e estágios iniciais de regeneração. Contudo predominância de espécies pioneiras em bancos de sementes do solo já foi observada em vários estudos realizados em Floresta Estacional Semidecidual, como de Franco (2005); Costalonga (2006); Martins (2009). Esses autores destacaram que o pioneirismo na maioria das vezes contribuirá na restauração florestal, uma vez que em poucos anos ocorrerá o recrutamento de outras espécies de estágios mais avançados de sucessão.

Essas famílias apresentam grande número de espécies herbáceas, forma de vida comumente presente em trabalhos com banco de sementes de comunidades florestais 
fragmentadas e cercadas de vegetação antropizada (Hopkins et al., 1990), como é o caso da área de estudo em questão.

\subsubsection{Diversidade de espécies}

Quanto à composição florística, quatro espécies demonstraram maior número de indivíduos, sendo elas, Cyperus brevifolius (89 indivíduos), Fimbristylis miliacea (75), Bidens pilosa (50) e Conyza bonariensis (21). Além de uma espécie identificada somente em nível de gênero, Paspalum sp. (216 indivíduos).

Comparado a outros estudos realizados os autores Maia et al., (2003), Souza et al., (2006); Lau e Jardim (2014); Costa (2017), apontaram a ocorrência de pelo menos uma das espécies supracitadas do tipo herbáceo, sendo assim, corrobora a ocorrência delas no banco de sementes amostrado. Vale ressaltar que o alto padrão de espécies pioneiras pode ser referente à área em entorno apresentar ocorrência de atividades agropecuárias e remanescentes florestais degradados, podendo então configurar-se em um problema, ou seja, dificultar nos processos sucessionais e consequentemente a regeneração natural.

A alta incidência de espécies do gênero Paspalum sp. pode estar diretamente relacionada ao tipo de uso e ocupação do solo. De acordo com Machado et al. (2013), em um banco de sementes que predominam a ocorrência de espécies desse gênero, o processo de recuperação e sucessão ecológica é retardado principalmente pela alta ocorrência de gramíneas.

\subsubsection{Diversidade de Formas de Vida}

O banco de sementes analisado apresentou como maior predominância de espécies herbáceas, com $56,4 \%$, seguida das arbóreas, com $0,9 \%$. As espécies mais representativas foram Cecropia pachystachya, cuja ocorrência pode proporcionar condições de sombreamento favoráveis à germinação de outras espécies, dando chances de recuperação ao ecossistema submetido a distúrbios antrópicos (Figueiredo, 2011) e Bauhinia variegata, considerada pioneira tardia na escala de sucessão ecológica, apresenta crescimento moderadamente rápido que é fundamental no processo de recuperação de áreas degradadas (Lorenzi, 1992). A única espécie que representou o 
estrato arbustivo foi a Chromolaena odorata com $0,4 \%$ a presença da mesma pode ser caracterizada por estar próximo a fragmentos de campo sujo (EMBRAPA, 2015).

Onde $42,3 \%$ dos indivíduos quantificados ficaram quanto a forma de vida indeterminados, sendo os mesmos identificados apenas em nível de gênero, como no caso Paspalum sp., que contribuindo com a segunda maior quantidade de indivíduos neste banco de sementes, conforme demonstra a (Figura 3).

Figura 3- Forma de vida das espécies ocorrentes no banco de sementes do Córrego Criminoso

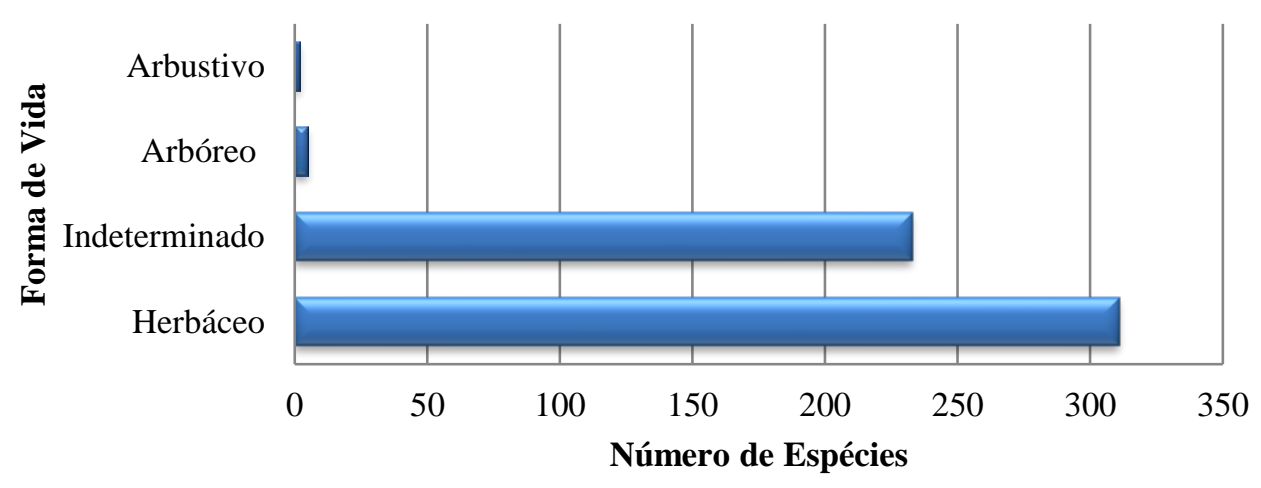

Fonte: Elaborado pelos autores.

Baider et al. (2001) diz que, para haver o amadurecimento da floresta deve-se ocorrer a diminuição das espécies herbáceas, assim fazendo com que haja o aumento da densidade de espécies arbustivas e arbóreas. No entanto neste estudo as espécies arbustivas e arbóreas, estiveram entre as menores ocorrências, como a arbustiva Chromolaena odorata (2 indivíduos) e as arbóreas Bauhinia variegata (1) e Cecropia pachystachya (4).

O destaque em densidade de espécies herbáceas levantadas na área de estudo, pode ser atribuído em função da área já ter sido antropizada, como também o tipo de manejo utilizado no local, além do entorno ser constituído por áreas de pastagens comprometendo assim o desenvolvimento da regeneração natural. De acordo com Junior et al., (2011) a baixa presença de espécies arbóreas e arbustivas pode ser explicada devido à presença de um grande número de espécies herbáceas, impedindo a formação de núcleos de vegetação e a conectividade entre fragmentos dificultando a germinação das mesmas.

Contudo no que consistem os tipos de uso do solo da microbacia existem inúmeras ameaças antrópicas que afetam o ambiente natural, como a expansão urbana e o uso 
agropecuário na região. Essas atividades fragilizam as Áreas de Preservação Permanente (APP) e os remanescentes florestais da área de estudo, prejudicando o processo de restauração e dificultando a dispersão de espécies florestais entre os fragmentos, que estão distribuídos muito esparsamente (Figura 4).

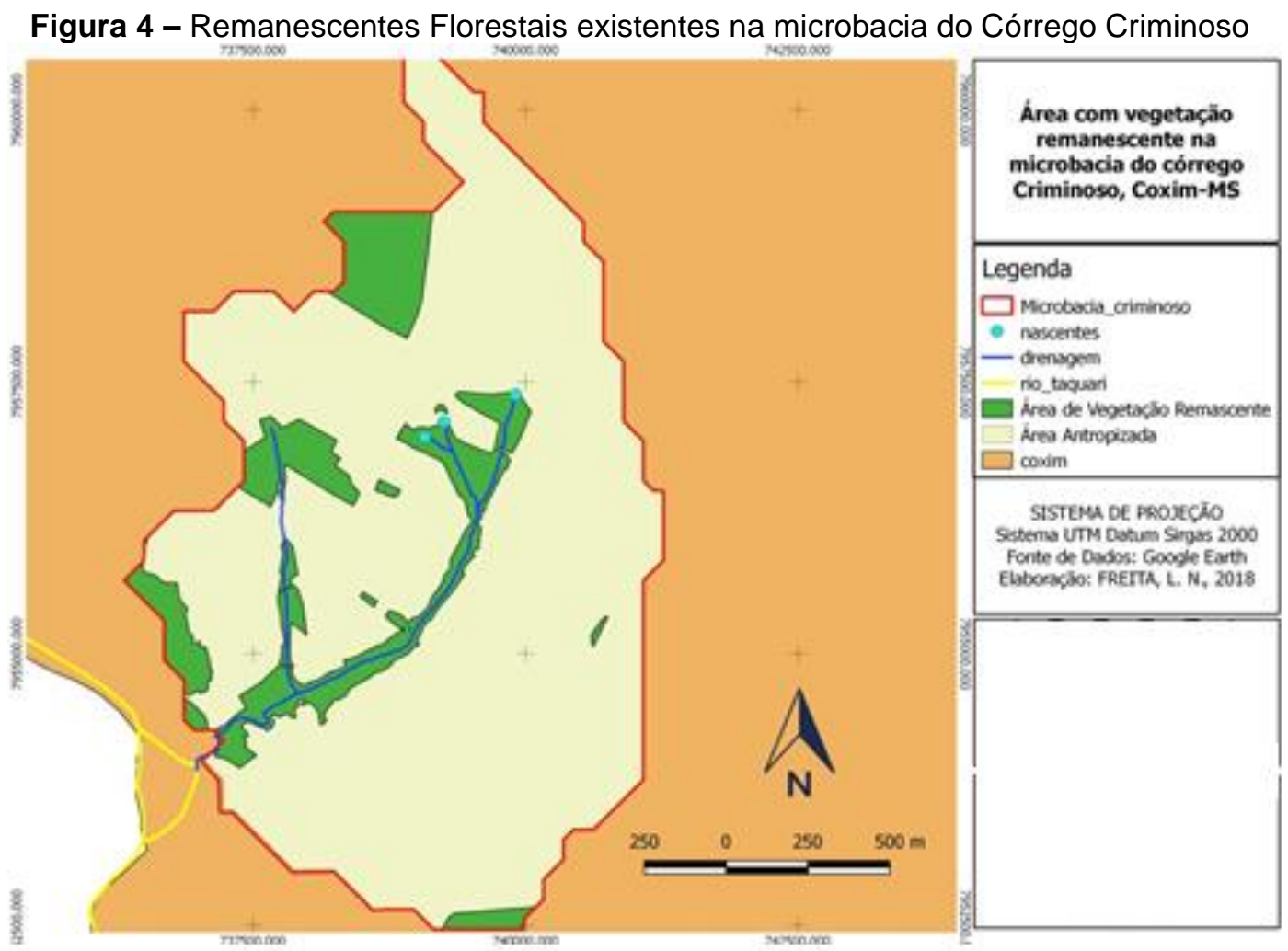

Fonte: Elaborado pelos autores.

Atualmente, grande parte dos remanescentes florestais encontra-se na forma de fragmentos alterados, desprotegidos. Isso se deve geralmente, devido às influências antrópicas que circundam a área no entorno desses fragmentos (SANTANA et al., 2004).Sendo assim, a conservação de fragmentos se torna muito importante, pois o mesmo irá contribuir para a estrutura da vegetação e da disposição da serrapilheira, de modo que, enriqueça o banco de sementes do local e, consequentemente, propicie condições para o fluxo de animais dispersores, fazendo com que as condições de regeneração sejam mais eficazes (SILVA et al., 2007).

No caso da microbacia de estudo, além de pastagens e agricultura, a área de preservação permanente (APP) ainda é constituída por eucaliptos, o que não auxilia no incremento da diversidade de espécies do banco de sementes, além de toda a APP sofrer constante pressão pelo avanço da urbanização. 


\subsubsection{Origem das Espécies}

No que consiste a origem das espécies identificadas no banco, ocorreu alta densidade de espécies nativas, cerca de $46,3 \%$, além $9,2 \%$ de espécies naturalizadas. Das identificadas a que possuiu o menor índice foram às exóticas obtendo apenas 2,2\% os outros $42,3 \%$ se delimitaram a categoria indeterminado (5). Essa alta quantidade de origem indeterminada se deu já que estas foram identificadas apenas a nível de gênero e não foi possível a determinação da sua origem, porém destaca-se que o gênero Paspalum é representado por ampla presença de espécies nativas e naturalizadas.

Figura 5 - Origem das espécies ocorrentes no banco de sementes do Córrego Criminoso

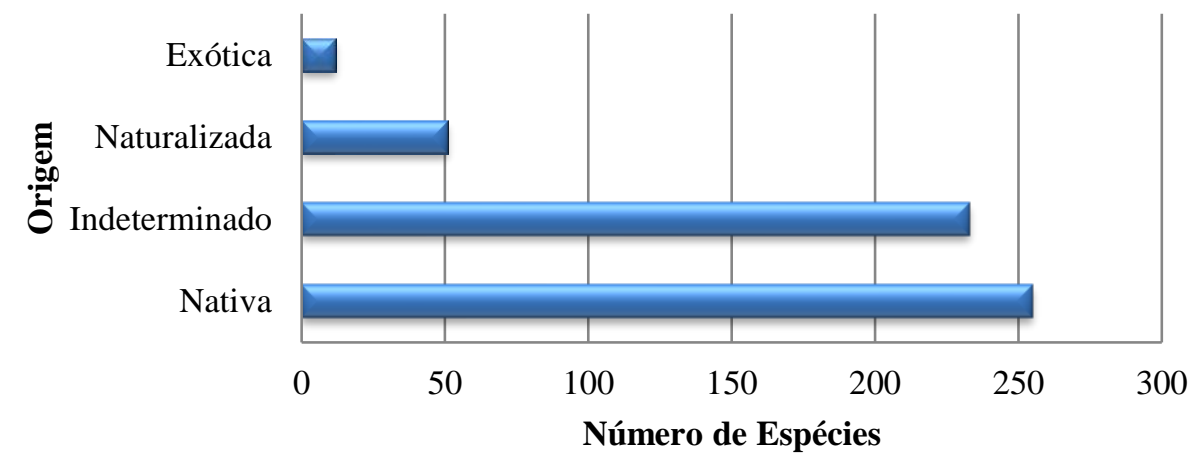

Fonte: Elaborado pelos autores.

O banco de sementes mostrou a dominância de espécies nativas e de algumas naturalizadas. De acordo com Weber et al., (2012) essa dominância é importante pois estimula o processo de sucessão em áreas com perturbações antrópicas. Houve também um pequeno quantitativo de indivíduos da espécie exótica Urochloa decumbens pertencente á família Poaceae, esse fato chama a atenção para a necessidade de desenvolvimento e aplicação de técnicas de controle de espécies invasoras, até que o banco ofereça condições para seu estabelecimento (BERTACCHI, 2008).

\subsubsection{Síndrome de Dispersão}

Em relação à síndrome de dispersão as anemocóricas alcançaram $51 \%$ obtendo a maior porcentagem, já as autocóricas e zoocóricas apresentaram, respectivamente, 5,4\% e 1,3\%. Assim como na forma de vida a síndrome de dispersão teve boa representatividade no número de indivíduos indeterminados correspondendo especificamente a $42,3 \%$ do 
banco de sementes, sendo relacionado à predominância do gênero Paspalum, que por sua vez deve ter se estabelecido pela ação do vento, já que a síndrome de dispersão desse gênero, na maioria das vezes, é anemocórica (Regensburguer et al., 2008) conforme a Figura 6.

Figura 6 - Síndrome de Dispersão das espécies ocorrentes no banco de sementes do Córrego Criminoso

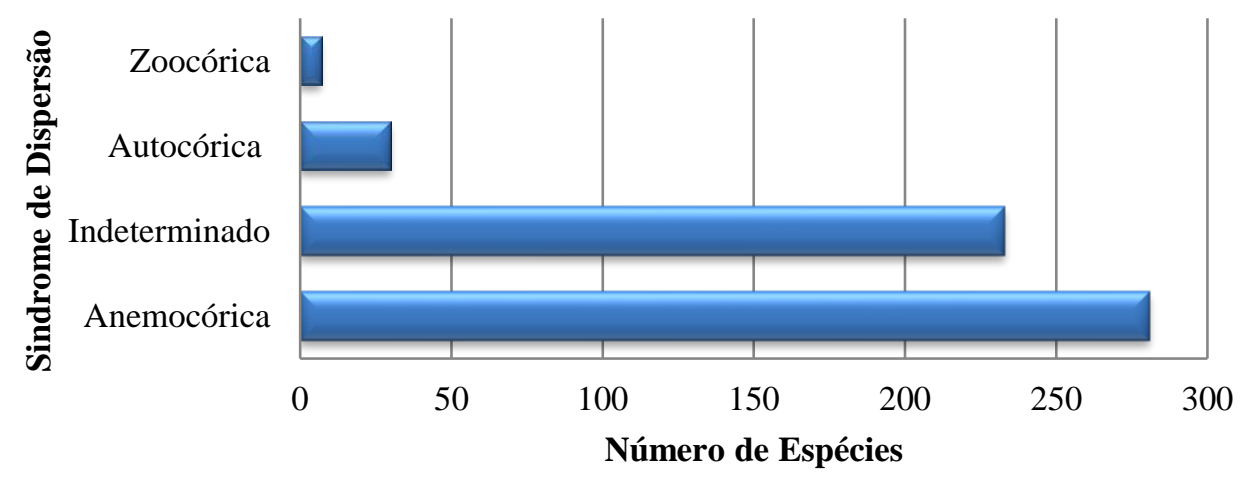

Fonte: Elaborado pelos autores

Esta alta porcentagem de espécies anemocóricas é dada principalmente pela família Asteraceae pela espécie Bidens pilosa da família Cyperaceae pela espécie Cyperus brevifolius, já na disseminação por autocóricas são as famílias Cyperaceae e Fabaceae respectivamente pelas Cyperus Luzulae E Mimosa pudica, no que tange a dispersão por zoocórica a família que se destaca é Solanaceae pela espécie Solanum americanum.

De acordo com Mantovani e Martins (1988); Batalha e Mantovani (2000); Batalha e Martins (2004), em se constando que a frutificação de espécies zoocóricas ocorre mais na estação chuvosa e de espécies anemocóricas autocóricas e na época da seca, as espécies encontradas no banco de sementes do Córrego Criminoso pode estar associada a essa teoria, já que a coleta foi realizada na estação seca, podendo estar associada ao vento, que seria mais forte nessa época do ano.

\subsection{5 Índice de Diversidade de Shannon $\left(H^{\prime}\right)$}

O banco de sementes do Córrego Criminoso obteve como resultado $\mathrm{H}^{\prime}=0,90$ para o índice de diversidade de Shannon $\left(\mathrm{H}^{\prime}\right)$, nesta área que corresponde ao domínio fitogeográfico do Cerrado.

Em estudo realizado por Machado et al. (2013) em área de domínio do Cerrado teve como resultado de $H^{\prime}=1,94$ na estação seca e de $H^{\prime}=1,88$ em estação pluviosa, 
apresentando também um baixo índice de diversidade. Comparando ao banco de sementes do Córrego Criminoso o mesmo mostrou-se um banco sementes com predominância de espécies herbáceas, não demonstrando resiliência quanto a regeneração natural, vez que o banco de sementes do córrego Criminoso foi avaliado apenas na estação da seca.

De acordo Saporetti Jr. et al., (2003) áreas com valores de índice de diversidade de Shannon acima de 3,11, já são consideradas com uma boa conservação. Estudos realizados em outros bancos de sementes como Ferreira et al., (2010) em área em processo de restauração, obtiveram o índice H'= 2,96 e Araújo et al., (2006), encontraram H'= 2,75 em uma área degrada por mineração, desse modo os valores demonstram que as áreas apresentam maior equilíbrio entre as abundâncias dos indivíduos e, consequentemente, maior diversidade.

O índice obtido no córrego Criminoso é considerado baixo quando comparado a outras áreas de Cerrado bem conservado, onde o mesmo apresenta dominância por gramíneas, o baixo índice de diversidade pode estar ligado à área de entorno que devido a algumas perturbações antrópicas, pode estar dificultando nos processos sucessionais. De acordo Ikeda et al., (2008) as queimadas também podem proporcionar essa baixa diversidade no banco de sementes.

\section{CONCLUSÃO}

Notou-se que a composição do banco de sementes da área de estudo é formada predominantemente por espécies herbáceas nativas. Sendo também constatadas espécies arbustivas e arbóreas, porém em pequena quantidade.

Para que ocorra uma recuperação da área é necessário aplicação do manejo adequado, já que o banco de sementes apresentou maior número de espécies herbáceas. Além disso foi frequente a ocorrência da espécie exótica Urochloa decumbens.

O banco de sementes do Córrego Criminoso possui uma diversidade florística baixa. A reduzida quantidade de fragmentos florestais no entorno da nascente compromete a conectividade entre os remanescentes prejudicando um maior enriquecimento do banco de sementes e consequente eficácia da regeneração natural. 


\section{REFERÊNCIAS}

ALVARENGA, A. P.; BOTELHO, S. A.; PEREIRA, I. M. Avaliação da regeneração natural na recomposição de mata ciliares em nascentes na região sul de Minas Gerais. Cerne, Lavras, v. 12, n. 4, p. 360 - 372, 2006.

ARAÚJO, F. S. de; MARTINS, S. V.; MEIRA NETO, J. A. A.; LANI, J. L.; PIRES, I. E. Estrutura da vegetação arbustivo-arbórea colonizadora de uma área degradada por mineração de Caulim, Brás Pires, MG. Revista Árvore, v. 30, p. 107 - 116, 2006. https://doi.org/10.1590/S0100$\underline{67622006000100013}$

ANDRADE, A. L. P Caracterização da chuva e do banco de sementes do solo em fisionomias campestres no sul do Brasil. Universidade Federal do Paraná, Setor de Ciências Agrárias, Programa de Pós- Graduação em Engenharia Florestal, p.137 Curitiba. Doutorado (Tese de Doutorado em conservação da Natureza), 2015.

APG (Angiosperm Phylogeny Group) IV. An update of the Angiosperm Phylogeny Groupclassification for the orders and families of flowering plants: APG IV. Botanical Journal of the Linnean Society, v.181, n. 1, 2016.

BATALHA, M. A. \& MANTOVANI, W. Reproductive phenological patterns of cerrado plant species at the Pé-de-Gigante Reserve (Santa Rita do Passa Quatro, SP, Brazil): A comparison between the herbaceous and woody floras. Revista Brasileira de Biologia p.129-145, 2000. https://doi.org/10.1590/S0034-71082000000100016

BAIDER, C.; TAABARELLI, M.; MANTOVANI, W. The soil seed bank during Atlantic forest regeneration in southeast Brazil. Revista Brasileira de Biologia. v.61, n. 1, p.35-44, 2001. https://doi.org/10.1590/S0034-71082001000100006

BATALHA, M. A. \& MARTINS, F.R. Reproductive phenology of the cerrado plant community in Emas National park (Central Brazil). Australian Journal of Botany p.149 - 161, 2004.

BRAGA, A, J.T; GRIFFITH, J. J; PAIVA, H.N; MEIRA, A,A. Composição do banco de sementes de uma floresta semidecidual secundária considerando o seu potencial de uso para recuperação ambiental. Revista Árvore, Viçosa-MG, v. 32, n. 6, p.1089-1098, 2008.

https://doi.org/10.1590/S0100-67622008000600014

BRASIL. 1990. Mapa multi-referencial do Estado de Mato Grosso do Sul. Brasília, IBGE. 1990. BRASIL. Lei no9.985, de 18 julho de 2000. Regulamenta o art. 225, § 1으, incisos I, II, III e VII da Constituição Federal, institui o Sistema Nacional de Unidades de Conservação da Natureza e dá outras providências. Disponível em: http://www.planalto.gov.br/ccivil 03/leis/L9985.htm. Acesso em: 05 jun. 2018.

BRASIL. Resolução SMA 08, de 31 de janeiro de 2008. Fixa a orientação para o reflorestamento heterogêneo de áreas degradadas e dá providências correlatas. Disponível em:

http://www.unisalesiano.edu.br/salaEstudo/materiais/p295892d7730/material7.pdf. Acesso em: 06 nov. 2018

BERTACCHI, M. I. F. Avaliação do potencial do banco de sementes para recuperação de áreas degradadas. Trabalho de conclusão de curso (Bacharelado em Ciências Biológicas) Universidade Estadual Paulista "Julio de Mesquita Filho", Botucatu, p.47, 2008. 
BROWN, D. Estimating the composition of a forest seed bank: a comparison of the seed extraction and seedling emergence methods. Canadian Journal of Botany, v. 70, p. 1603-1612, 1992.

COSTALONGA, S. R. Banco de sementes em áreas contíguas de pastagem degradada, plantio de eucalipto e floresta natural, em Paula Cândido - MG. 2006. f.126 Dissertação (Mestrado em Ciência Florestal) - Universidade Federal de Viçosa, Viçosa, MG, 2006.

COSTA, P. F. Indicadores ecológicos no monitoramento de áreas em processo de restauração florestal localizadas no sul do estado do Mato Grosso do Sul-MS. Universidade Federal da Grande Dourados, Faculdade de Ciências Exatas e Tecnologias, p.140 Dourados (Tese de Doutorado em Ciência e Tecnologia Ambiental), 2017.

CHAMI, L. B. Vegetação e mecanismos de regeneração natural em diferentes ambientes da Floresta Ombrófila Mista na FLONA de São Francisco de Paula, RS. f.121 Dissertação (Mestrado em Engenharia Florestal) - Universidade Federal de Santa Maria, Santa Maria, 2008.

EMBRAPA 2015. Bioma cerrado: cerrado campo sujo. Disponível em: http://www.agencia.cnptia.embrapa.br/Agencia16/AG01/arvore/AG01 4991120058 5233.html. Acesso em: 10 out. 2018.

FERREIRA, W. C.; BOTELHO, S. A.; DAVIDE, A. C.; FARIA, J. M. R.; FERREIRA, D. F. Regeneração natural como indicador de recuperação de área degradada a jusante da Usina Hidrelétrica de Camargos, MG. Revista Árvore p. 651-660, 2010. https://doi.org/10.1590/S0100$\underline{67622010000400009}$

FIGUEIREDO, P. H. A.; MIRANDA, C.C.; MATHEUS, F. A.; VALCARCEL, R. Avaliação do potencial seminal da Cecropia Pachystachya Trécul no banco de sementes do solo de um fragmento florestal em restauração espontânea na Mata Atlântica, Pinheiral - RJ. Revista Biociências da Universidade de Taubaté, 2011.

FRANCO, B. K. S. Análise da regeneração natural e do banco de sementes em um trecho de floresta estacional semidecidual no campus da Universidade Federal de Viçosa, MG. 2005. f.73 Dissertação (Mestrado em Ciência Florestal) - Universidade Federal de Viçosa, Viçosa, MG, 2005.

GROSS, K. L. A. A comparison of methods for estimating seed numbers in the soil. Journal of Ecology, v. 78, p. 1079-1093, 1990.

GUNTZEL, A. M.; DIAS, N. R.; COERTJENS, C. M.; SILVA, G. C.; VIEIRA, E. A. Análise fitossociológica de um remanescente de vegetação na microbacia do Córrego Criminoso (Bacia do Rio Taquari, Coxim, MS, Brasil): subsídios para a recomposição da vegetação. Acta Botânica Brasílica, Feira de Santana, v. 25, n. 3, p. 586-592, 2011. https://doi.org/10.1590/S010233062011000300011

HOPKINS, M. S.; TRACEY, J. G.; GRAHAM, A. W. The size and composition of soil seed banks in remmant patches of three structural rainforest types in North Queensland, Australia. Australian Journal of Ecology, v.15, n.1, p. 43-50, 1990. https://doi.org/10.1111/j.1442-9993.1990.tb01019

IKEDA, F. S., MITJA, D., VILELA, L., Silva, J. C. S. Banco de sementes em cerrado sensu stricto sob queimada e sistemas de cultivo. Pesquisa Agropecuária Brasileira. v.43, n.6, p.667-673, 2008.https://doi.org/10.1590/S0100-204X2008000600001

INSTITUTO BRASILEIRO DE GEOGRAFIA E ESTATÍSTICA-IBGE. Cidades, 2010. Disponível em: https://cidades.ibge.gov.br/brasil/ms/coxim/panorama. Acesso em: 25 jul. 2018. 
JUNIOR, H. F. B.; VALCARCEL, R.; ROPPA, C.; NETTESHEIM, F. C. Levantamento de espécies rústicas em áreas de pastagem e em remanescente florestal na Mata Atlântica, Piraí-RJ. Floresta e Ambiente, p.50-59, 2011. http://dx.doi.org/10.4322/floram.2011.022

KOHLRAUSCH, F.; JUNG, C, F. Áreas Ambientais degradadas: causas e recuperação, p.16, 2015.

LAU, A. V.; JARDIM, M. A. G. Composição e densidade do banco de sementes em uma floresta de várzea, Ilha do Combu, Belém-PA, Brasil. Biota Amazônia, v. 4, n. 3, p. 5-14, 2014.

http://dx.doi.org/10.18561/2179-5746/biotaamazonia.v4n3p5-14

LEFB. Lista de Espécies da Flora do Brasil. Disponível em:

http://floradobrasil.jbri.gov.br/reflora/listaBrasil/PrincipalUC/PrincipalUC.do\#CondicaoTaxonCP.

Acesso em: 09 de maio 2018.

LORENZI, H. Árvores brasileiras. Manual de identificação e cultivo de plantas arbóreas nativas do Brasil. Nova Odessa: p.352. 1992.

MARTINS, S. V. Recuperação de áreas degradadas: ações em Áreas de Preservação Permanente, voçorocas, taludes rodoviários e de mineração. Viçosa, MG: Ed.Aprenda Fácil, p. 270, 2009.

MANTOVANI, W e MARTINS, F.R. Variações fenológicas das espécies do cerrado da Reserva Biológica de Mogi Guaçu, Estado de São Paulo. Revista Brasileira de Botânica. p. 101 - 112, 1988.

MAGURRAN, A. E. Ecological diversity and its measurement. Londres: Princeton University Press, p.192, 1988.

MAIA, F. C.; MEDEIROS, R. B.; PILLAR, V. P., CHOLLET, D. M. S., OLMEDO, M. O. M. Composição, riqueza e padrão de variação do banco de sementes do solo em função da vegetação de um ecossistema de pastagem natural, 2003.

MACHADO, V. M., SANTOS, J. B., PEREIRA, I. M., LARA, R. O., CABRAL, C. M. \& AMARAL, C. $\mathrm{S}$. Avaliação do banco de sementes de uma área em processo de recuperação em cerrado campestre. Planta Daninha, v. 31, n. 2, p. 303-312, 2013. https://doi.org/10.1590/S0100$\underline{83582013000200007}$

MINELLA, G, M; BUNDCHEN, M. Técnicas de nucleação aplicadas na recuperação de áreas degradadas. p.10, 2015.

NETO, A. M.; KUNZ, S. H.; MARTINS, S. V.; SILVA, K. A.; SILVA, D. A. Transposição do banco de sementes do solo como metodologia de restauração florestal de pastagem abandonada em Viçosa, MG. Revista Árvore, Viçosa, MG, v. 34, n. 6, p. 1035-1043, 2010. https://doi.org/10.1590/S0100-67622010000600009

OLIVEIRA, Y. M. M. de; ROTTA, E. Levantamento da estrutura horizontal de uma mata de araucária do primeiro planalto paranaense. Boletim de Pesquisa florestal, Colombo, n. 4, p.111, 1982.

OLIVEIRA, P. E. A. M.; PAULA, F.R. Fenologia e biologia reprodutiva de plantas de matas de galeria. In: RIBEIRO, J.F.; FONSECA, C.E.L.; SOUSA-SILVA, J.C. Cerrado: caracterização e recuperação de Matas de Galeria. Planaltina: EMBRAPA Cerrados, p. 303-328. 2001. 
REGENSBURGUER, B.; COMIN, J. J.; AUMOND, J. J. Integração de técnicas de solo, plantas e animais para recuperar áreas degradadas. Ciência Rural, v. 38, n. 6, p. 1773-1776, 2008.

SAPORETTI JR, A.; MEIRA NETO, J. A.; ALMADO, R. P. Fitossociologia de cerrado sensu stricto no município de Abaeté, MG. Revista Árvore, v. 27, n. 3, p.413-419. 2003.

SANTANA, C. A. A.; LIMA, C. C. D.; MAGALHÃES, L. M. S. Estrutura horizontal e composição florística de três fragmentos secundários na cidade do Rio de Janeiro. Biological Sciences Maringá, v. 26, n. 4, p. 443-451, 2004.

STEFANELLO, D.; IVANAUSKAS, N. M.; MARTINS, S. V.; SILVA, E.; KUNZ, S. H. Síndromes de dispersão de diásporos das espécies de trechos de vegetação ciliar do rio das Pacas, Querência MT. Acta Amazônica, Manaus, v. 40, n. 1, 2010. https://doi.org/10.1590/S0044$\underline{59672010000100018}$

SILVA, W. C., MARANGON, L. C.; FERREIRA, R. L. C.; FELICIANO, A. L. P.; JUNIOR,R. F. C. Estudo da regeneração natural de espécies arbóreas em fragmento de Floresta Ombrófila Densa, Mata das Galinhas, no município de Catende, Zona da Mata Sul de Pernambuco. Ciência florestal, Santa Maria, v.17, n. 4, p. 321-331, 2007. https://doi.org/10.5902/198050981964

SOUZA, M. L. de. Análise do banco de sementes no solo e da regeneração natural de um fragmento florestal com Araucária angustifólia (Bert.) O. Ktze., no estado do Paraná. f.115. Dissertação(Mestrado em Ciências Florestais) - Universidade Federal do Paraná, Curitiba, 1996.

SOUZA, P. A.; VENTURIN, N.; GRIFFITH, J. J.; MARTINS, S. V. Avaliação do banco de sementes contido na serrapilheira de um fragmento florestal visando recuperação de áreas degradadas.

Cerne, v. 12, n.1, p. 56-67, 2006.

VAN DER PIJL, L. Principles of dispersal in higher plants. 3rd ed. Berlin: Springer Verlag, p.215, 1982.

ZAVATTINI, J. A. As chuvas e as massas de ar no estado de Mato Grosso do Sul: estudos geográficos com vista à regionalização climática. São Paulo: Cultura Acadêmica, p.214, 2009.

WEBER, A. J. C. S.; NOGUEIRA, A. C.; CARPANEZZI A. A.; GALVÃO, F.; WEBER S. H. Composição florística e distribuição sazonal do banco de sementes em Floresta Ombrófila Mista Aluvial, Araucária, PR. Pesquisa Florestal Brasileira, v. 32. n.70, 2012. 